\title{
METAL INJECTION MOLDING OF ALLOY 718 FOR AEROSPACE APPLICATIONS
}

\author{
Takashi Yoshinouchi ${ }^{1}$, Nobuyasu Tsuno ${ }^{2}$, Shuji Ikeda ${ }^{1}$ and Hiroki Yoshizawa ${ }^{2}$ \\ ${ }^{1}$ Research \& Engineering Division, Aero-Engine \& Space Operations, IHI Corporation \\ 3975-18, Haijima-cho, Akishima-shi, Tokyo, 196-8686, JAPAN \\ ${ }^{2}$ Research laboratory, IHI Corporation \\ Shin-nakahara-cho, Isogo-ku, Yokohama-shi, Kanagawa, 235-8501, JAPAN
}

Keywords: Metal Injection Molding, MIM, Alloy718

\begin{abstract}
Alloy 718 is used extensively in aerospace engines due to its excellent properties at high temperature. Components are typically fabricated by machining processes to make complex shapes. However machining processes sometimes result in high manufacturing cost, because Alloy 718 is a difficult metal to shape. Material costs are also soaring in recent years, especially in superalloys. Therefore, net shape manufacturing is becoming a more and more important technology in order to reduce manufacturing cost. Metal Injection Molding (MIM) is the one of the solutions to reduce the cost of producing large amounts of small and complex metallic parts. IHI has been developing a MIM process for low cost manufacturing of high pressure compressor vanes which are used in aircraft gas-turbine engines. Material testing has been carried out and the high cycle fatigue data shows good performance. Size precision of the prototype compressor vane has shown promising results.
\end{abstract}

\section{Introduction}

Metal powder injection molding is also called Metal Injection Molding (MIM). MIM is a relatively new method that was developed in the 1970's [1]. Fine metal powder is mixed with thermoplastic resin called a binder and injection molded the same as plastic molding. The molding process allows complicated shapes. After injection molding, the binder is removed such as by solvent or heat. The resulting part is sintered at temperatures near to the melt temperature to obtain the final product. MIM parts generally show higher density than press and sinter powder metallurgy. It is possible to obtain a high strengths.

Heat-resistant nickel-based superalloys are difficult-to-cut materials which are used for compressor stator blades of jet engines. There is a tendency that a thin three-dimensional shape is applied to compressor blades for performance improvement. That requires a complex machinery process. Significant cost reduction effects can be expected if parts are manufactured by integrally molded by MIM.

On the other hand, MIM has been used mainly in electornic, medical, dental and automotive. Therefore iron-based alloys such as stainless steel are used in most applications. Some data of nickel-based heat-resistant alloys that are used in jet engines is available [2, 3]. Further, as component size increases, it becomes more difficult to keep dimensional accuracy. In order to apply the MIM to jet engine parts, it is necessary to improve these problems. 
A typical microstructure of MIM Alloy 718 is shown in Figure 1. That includes micro porosity. The particle sizes of the alloy powder significantly affects the grain size, porosity and the metal structure. Using more small powder, it is possible to improve sintering characteristics. But it brings about the specific surface area increase and higher content of oxygen. To apply the MIM process to the jet engine parts, it is important to understand the effect of the powder characteristics on the material strength of the components.

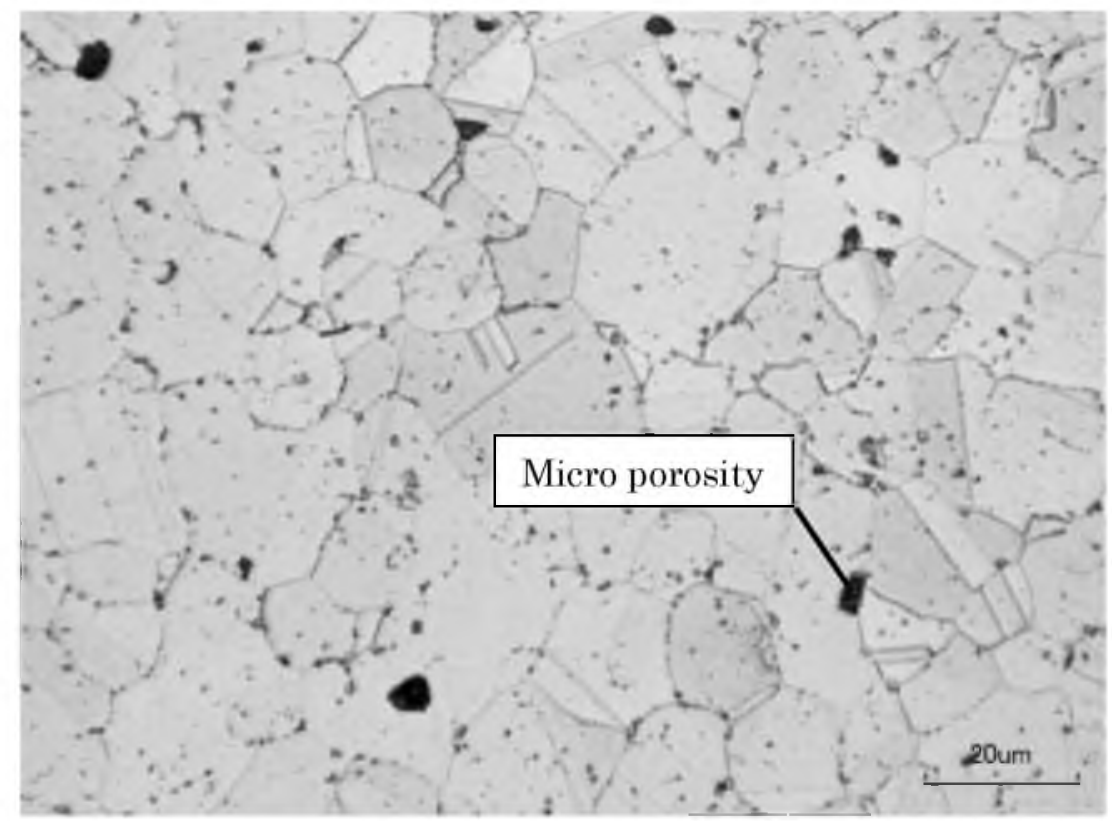

Fig. 1 Typical microstructure of MIM Alloy 718

After molding, de-binding and sintering process are necessary. Deformation occurs during these processes as shown in Figure 2. In the de-binding process, phase conversion of binder from solid to liquid becomes a factor in the deformation. The sintering process is carried out at high temperature that is near the melting point, which can cause creep deformation under its own weight. When component size becomes larger, it becomes more difficult to keep the dimensional accuracy of parts. Therefore, generally MIM is used for parts having less than about $100 \mathrm{~g}$. It is necessary to ensure the dimensional accuracy of larger parts to apply the MIM process for jet engine parts. It is problem to reduce deformation during de-binding and sintering process.

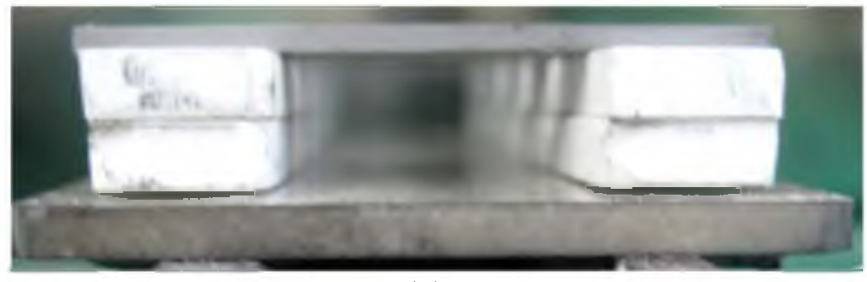

(a)

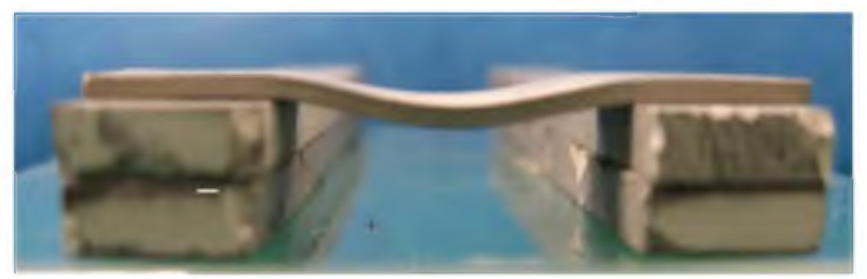

(b)

Fig2. Deformation during MIM process

(a) before de-binding (b) after sintering 
In this paper, material data were acquired using Alloy718 specimens which are prepared by MIM. In addition, prototype compressor vanes of a jet engine were produced using a binder. Deformation suppressing effect with large parts was confirmed. This paper shows trail manufacture result of compressor vanes and material data of Alloy $718 \mathrm{MIM}$.

\section{Experimental Procedure}

Fig. 3 shows the process of MIM. The MIM process involves combining Alloy718 metal powder (D90 $-22 \mu \mathrm{m}$ ) with binder to produce the feedstock. The feedstock is injected into a mold using plastic injection molding machine. The molded parts size should be calculated considering the shrink during post de-binding and sintering process. After molding, the binder is removed using solvent or heating process. The resulting parts are sintered at high temperature in a furnace.

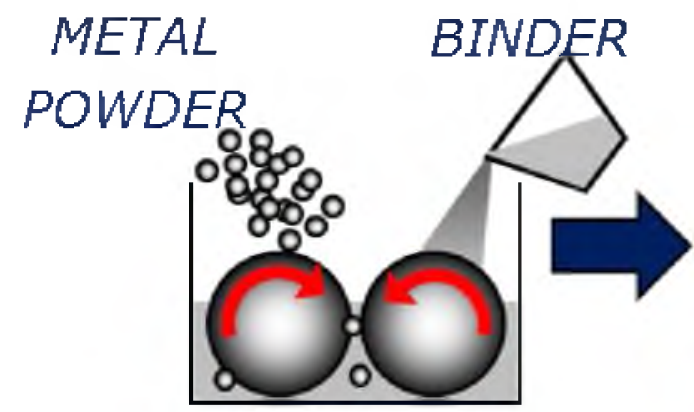

Mixing

Mix $<22 \mu \mathrm{m}$ metal powder with Binder (polymer \& wax)

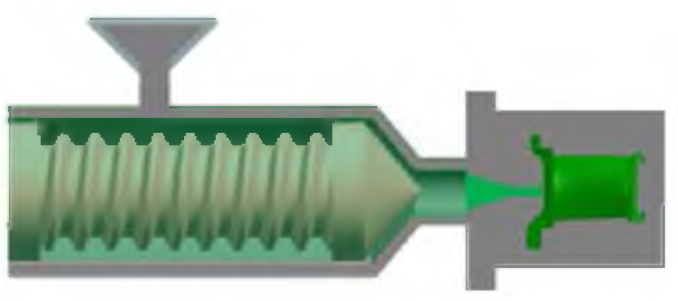

Molding

Mold components using standard plastic injection

molding equipment.

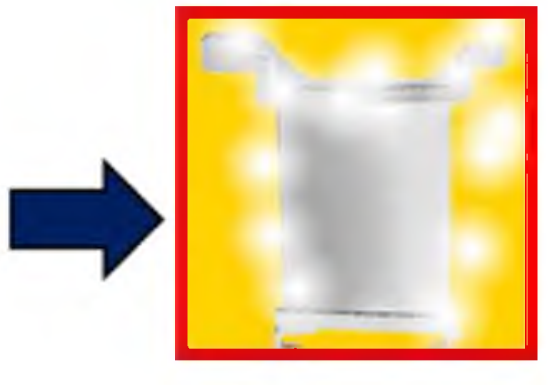

Debindina Remove binder by thermal process

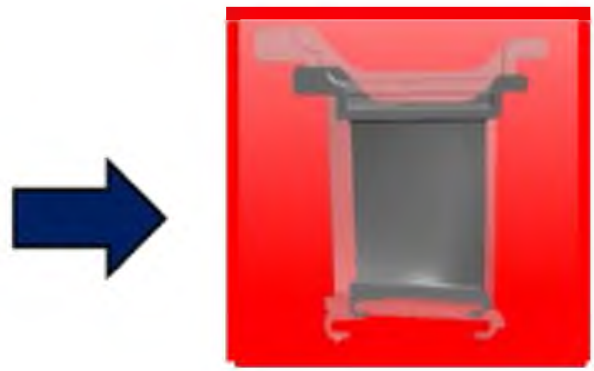

Sintering

Remove the remaining binder.

Fig3. MIM process 
Material Test

To ensure the material strength which is important in jet engine parts, they are required sufficient fatigue strength especially compressor stator vanes. In order to confirm the required high cycle fatigue strength of Alloy 718 with MIM process, fatigue and tensile tests were performed using test pieces as shown in Fig. 4. To investigate the effect of micro-porosity, additional fatigue tests were carried out using the test pieces that have an artificial defect about $\varphi 0.1 \mathrm{~mm}$ of the surface.

To confirm the effect of oxygen content, fatigue tests were carried out using gas atomization power and water atomization powder. Table 1 shows the oxygen concentration in the Alloy 718 metal powder.
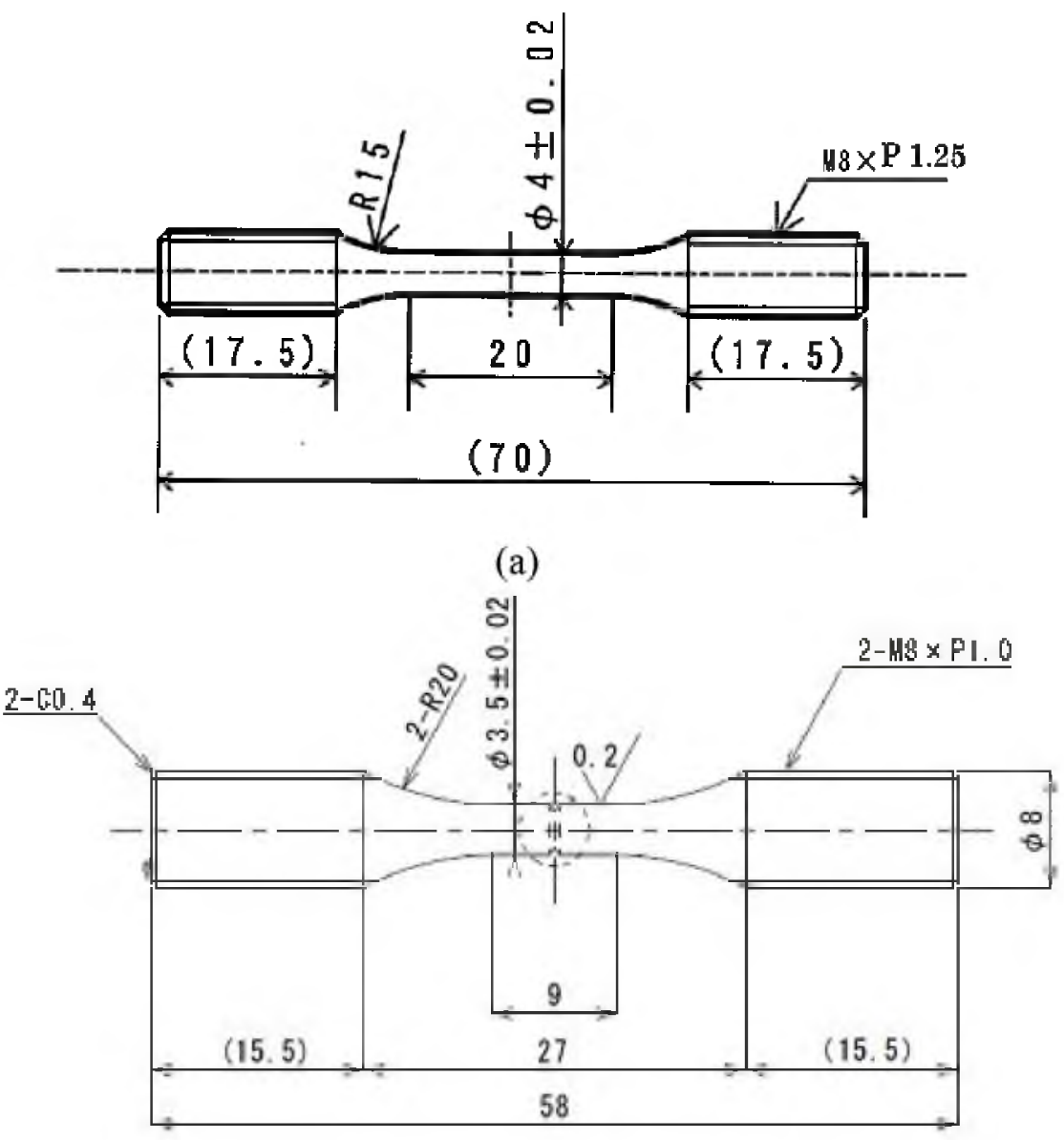

(b)

Fig.4 Geometry of the tensile and fatigue test bar (a) Test piece for Tensile (b) Test piece for Fatigue 
Table 1 Composition of Alloy718 metal powder

\begin{tabular}{l|c|c|c|c|c|c}
\hline $\begin{array}{l}\text { Produce } \\
\text { Method }\end{array}$ & $\begin{array}{c}\mathrm{Mo} \\
{[\%]}\end{array}$ & $\begin{array}{c}\mathrm{Al} \\
{[\%]}\end{array}$ & $\begin{array}{c}\mathrm{Ti} \\
{[\%]}\end{array}$ & $\begin{array}{c}\mathrm{Nb} / \mathrm{Ta} \\
{[\%]}\end{array}$ & $\begin{array}{c}\mathrm{O} \\
{[\mathrm{ppm}]}\end{array}$ & $\begin{array}{c}\mathrm{C} \\
{[\%]}\end{array}$ \\
\hline $\begin{array}{l}\text { Gas } \\
\text { Atomized }\end{array}$ & 3.12 & 0.66 & 0.98 & 5.14 & 300 & 0.05 \\
\hline $\begin{array}{l}\text { Water } \\
\text { Atomized }\end{array}$ & 3.02 & 0.27 & 0.73 & 5.01 & 4900 & 0.05 \\
\hline
\end{tabular}

\section{Prototype production of compressor stator vane}

Prototype compressor vanes of a jet engine were manufactured by the MIM process. Fig. 5 and Fig. 6 show a cross-sectional view of a jet engine, and the part geometry for compressor vanes. Usually, compressor stator vanes are produced by press molding and cutting, and assembled in a complex process to the component. The components are arranged on the circumference in a jet engine. The weight of the component is several hundred grams, therefore it is difficult to keep shape accuracy. To keep shape accuracy, a new binder is developed. Both the new and the convenstional binder are wax based, but the new binder has improved strength during the debinding process compared to the conventional binder. That improvement brings about size precision compared to conventional binder.
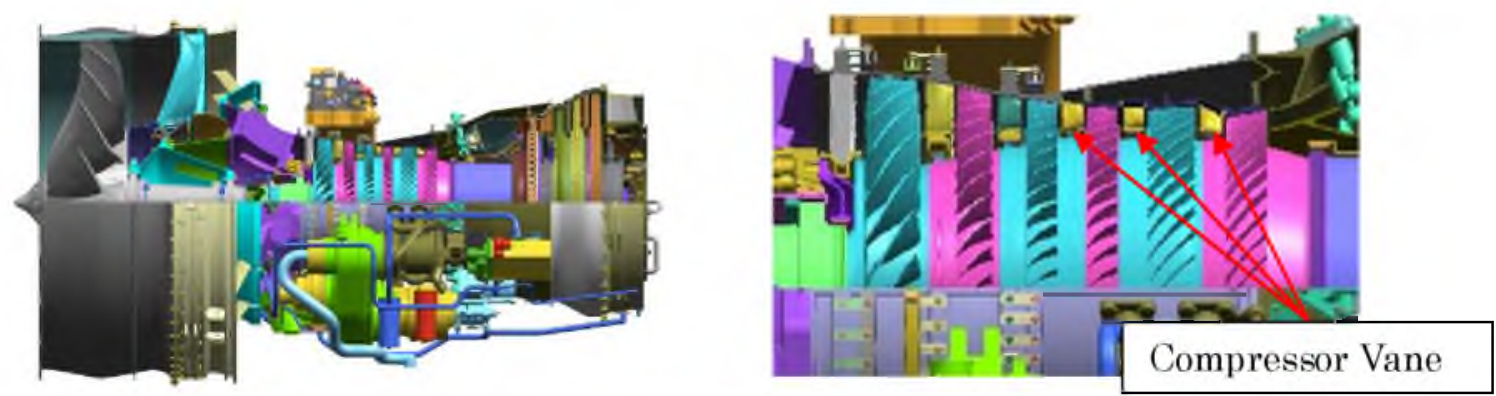

Fig. 5 Cross section view of aircraft gas-turbine engine

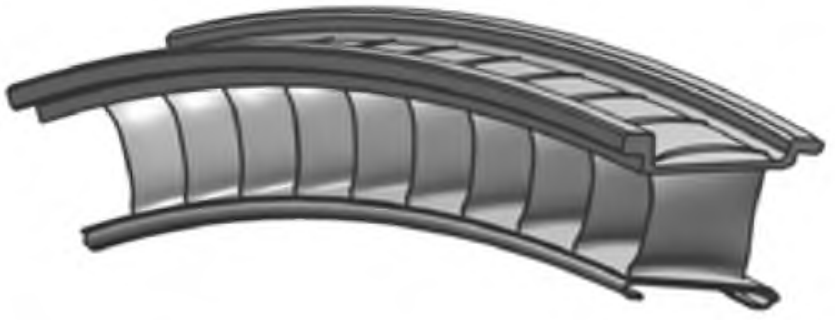

Fig.6 External view of compressor vane 


\section{Results}

\section{Material Test Results}

Fig. 7 to 9 show the results of tensile testing. Test pieces were manufactured using the new binder. Fig. 10 shows typical microstructure of the new binder and conventional binder. These microstructures are equivalent. Tensile strength of Alloy718 with MIM process is nearly equal to the forging. And it shows enough elongation for practical use. Fig. 11 also shows the fatigue test results. High cycle fatigue property requirements are significant for the compressor stator blade. Alloy 718 with MIM process shows excellent results, and its strength exceeded the forging. MIM parts typically contain several percent of porosity, but MIM parts show good performance for fatigue. A finer grain size of MIM parts brings about these results. Comparison of the grain size of MIM and forgings are shown in Table 2.

Meanwhile fatigue strength of MIM parts using water atomized powder including a high oxygen concentration are significantly reduced. Fig. 12 shows the fatigue test results of the specimen using gas atomized powder with the artificial surface defect of about $\varphi 0.1 \mathrm{~mm}$. It shows a strength equivalent to the test piece without the artificial defect. It was confirmed that surface defects of about $\varphi 0.1 \mathrm{~mm}$ do not affect fatigue strength.

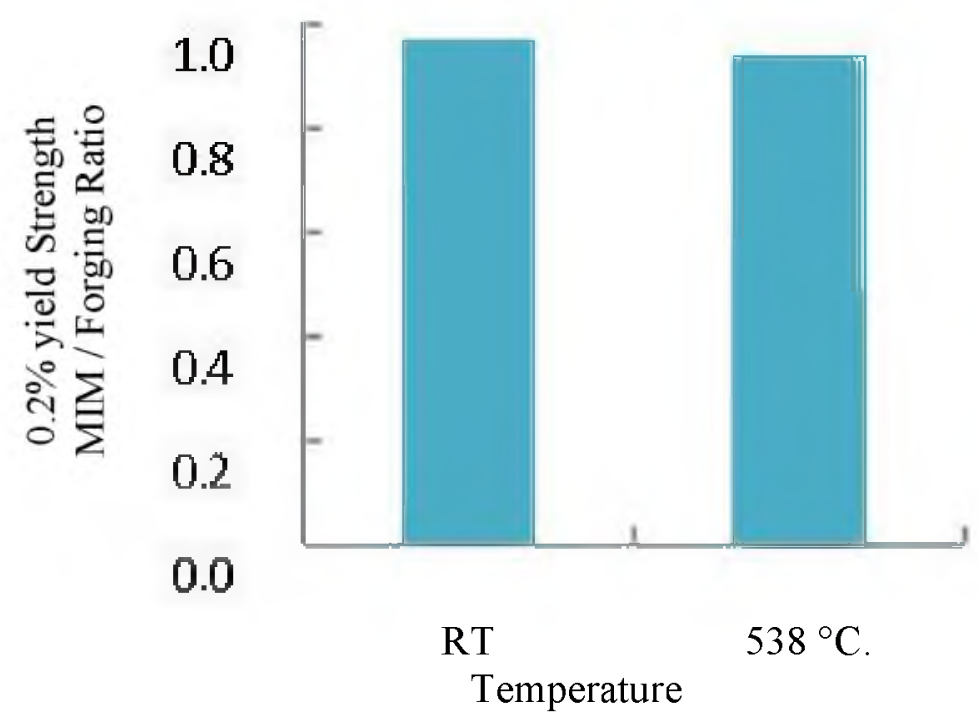

Fig. $70.2 \%$ yield strength of MIM alloy 718 compared to Forging. 


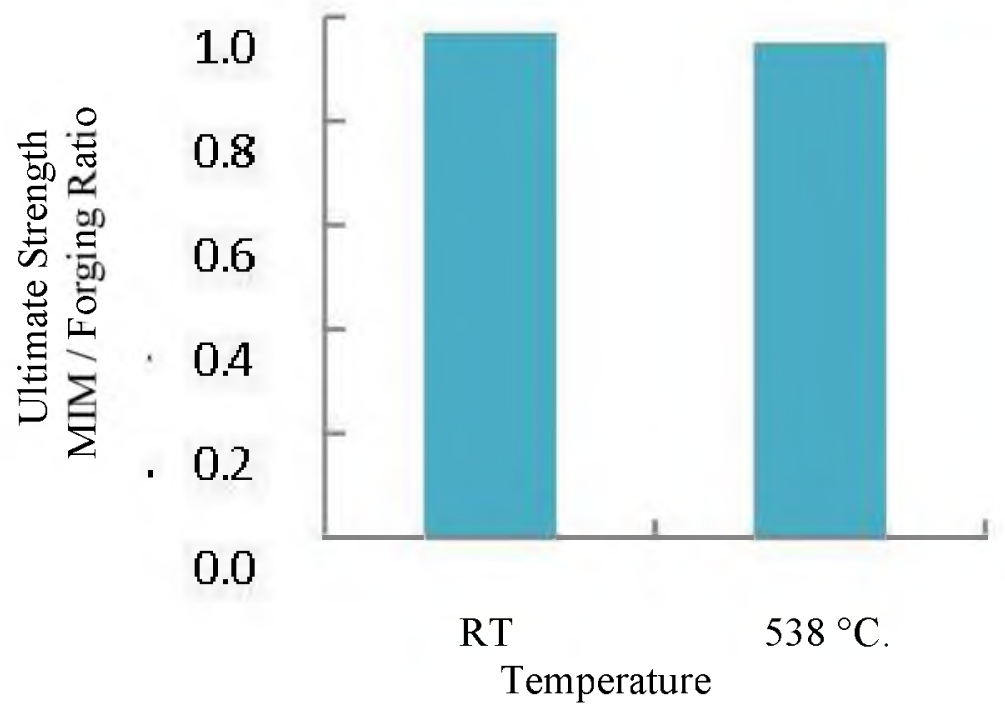

Fig.8 Ultimate strength of MIM alloy 718 compared to Forging.

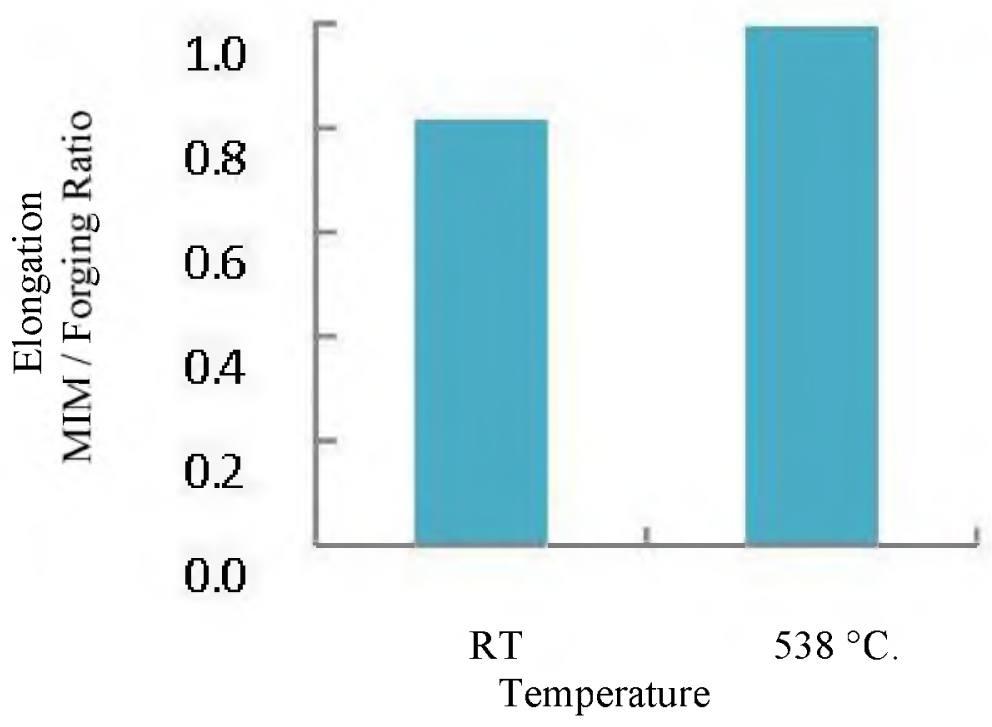

Fig.9 Elongation of MIM alloy 718 compared to Forging 


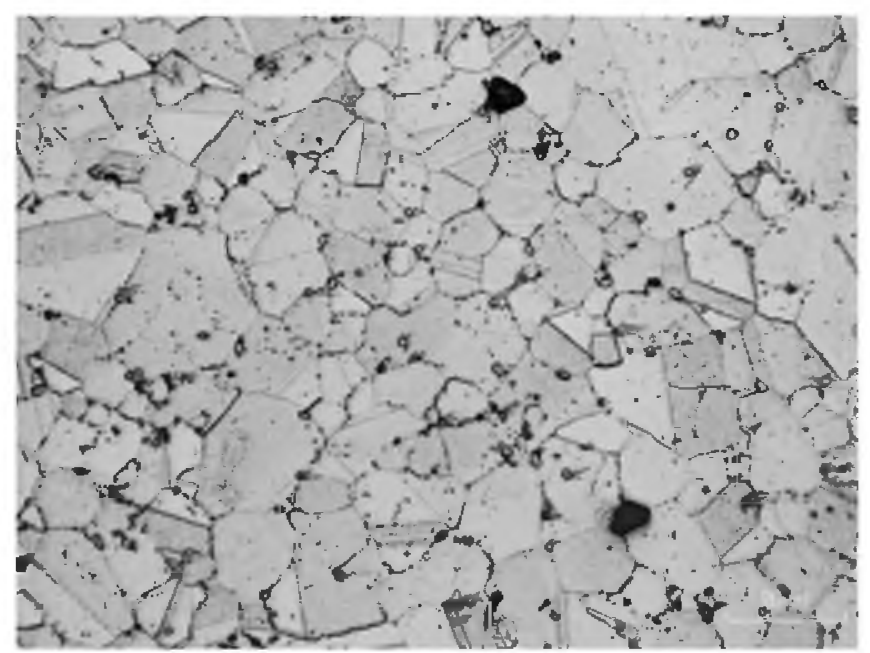

(a)

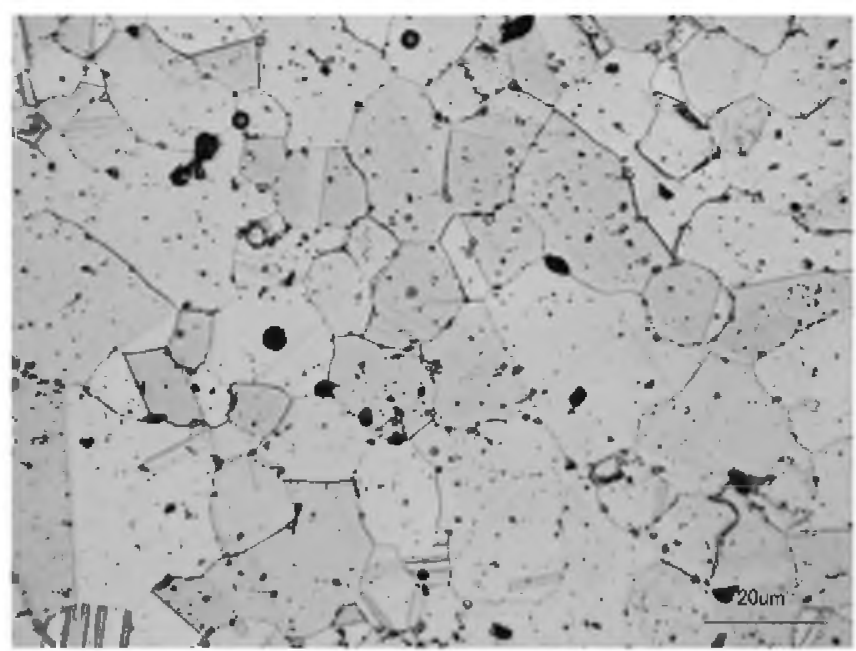

(b)

Fig.10 Typical microstructure of MIM alloy 718 (a) manufactured using new binder (b) manufactured using conventional binder

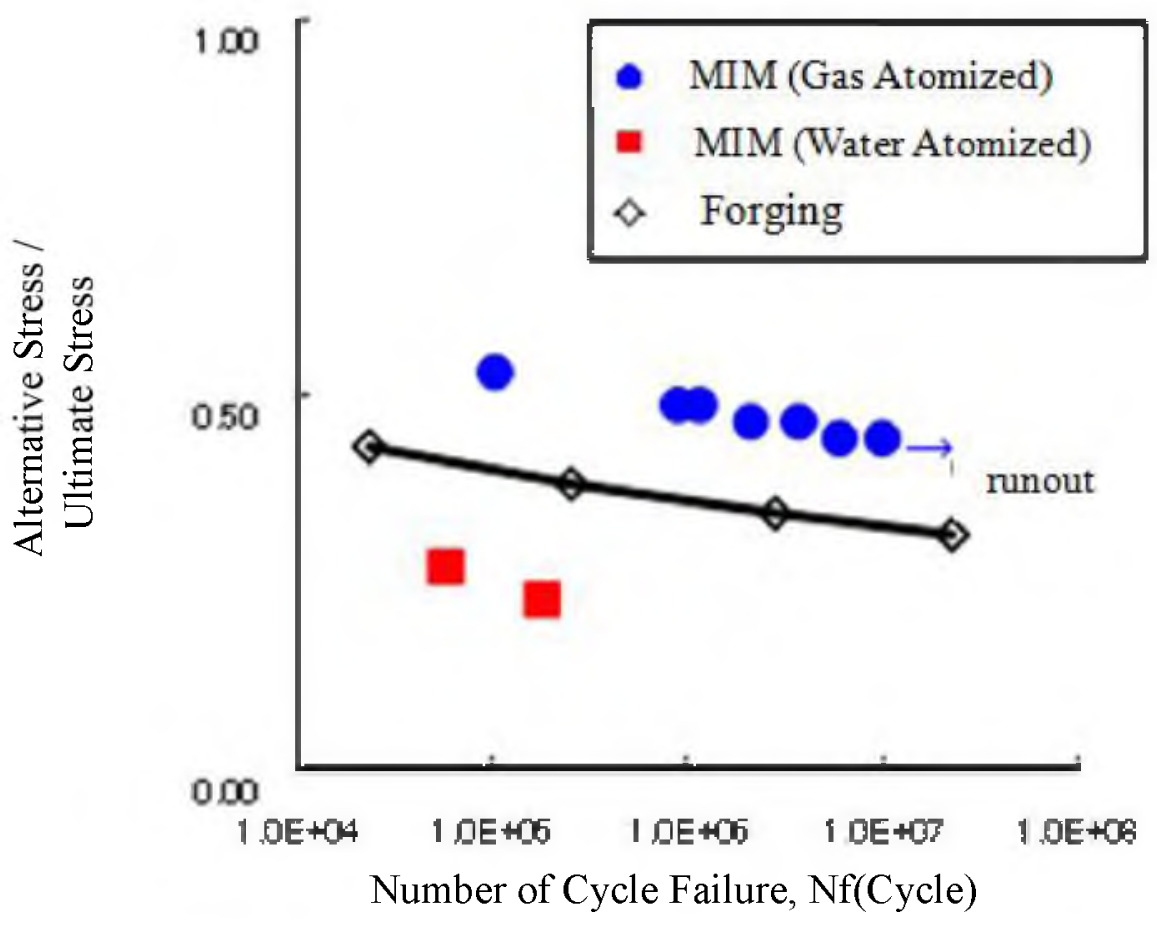

Fig. $11 \mathrm{~S}-\mathrm{N}$ Curve of MIM Alloy 718 at $538^{\circ} \mathrm{C} . \mathrm{R}=-1$ 
Table. 2 Comparison of grain size for Forged and MIM Alloy 718

\begin{tabular}{l|c}
\hline & $\begin{array}{c}\text { Grain Size } \\
\text { (um) }\end{array}$ \\
\hline Forging & 90 \\
\hline MIM & 30 \\
\hline
\end{tabular}

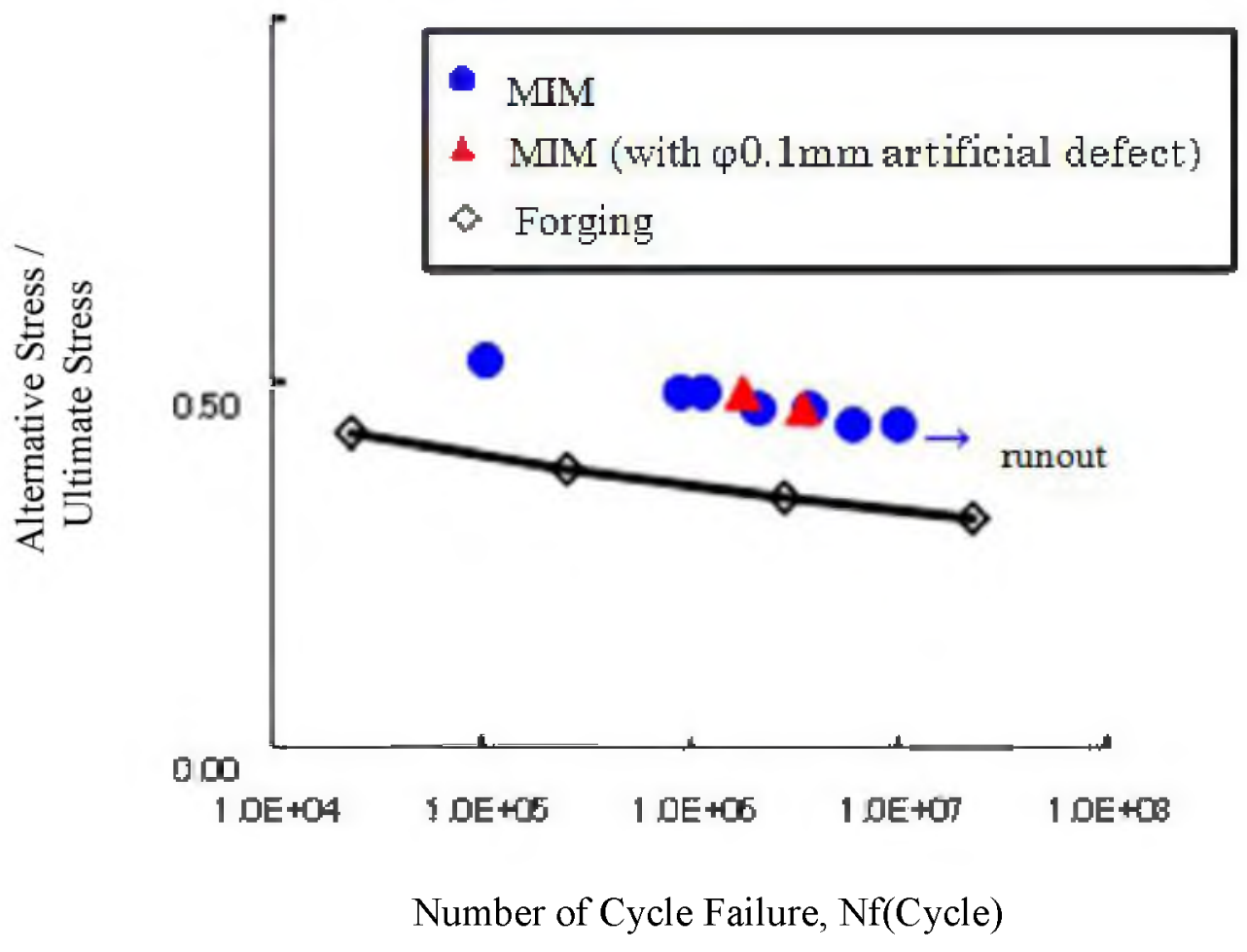

Fig. 12 S-N curve of MIM alloy 718 with artificial defect at $538^{\circ} \mathrm{C} . \mathrm{R}=-1$

\section{Prototype Compressor Stator Vane}

Fig. 13 shows the compressor stator vane that was manufactured by MIM using conventional binder. The deformation is large, and it does not satisfy the dimensional tolerance requirements. Fig. 14 shows the compressor stator vane that was manufactured by MIM using new binder. Size precision of new binder shows a promising result.

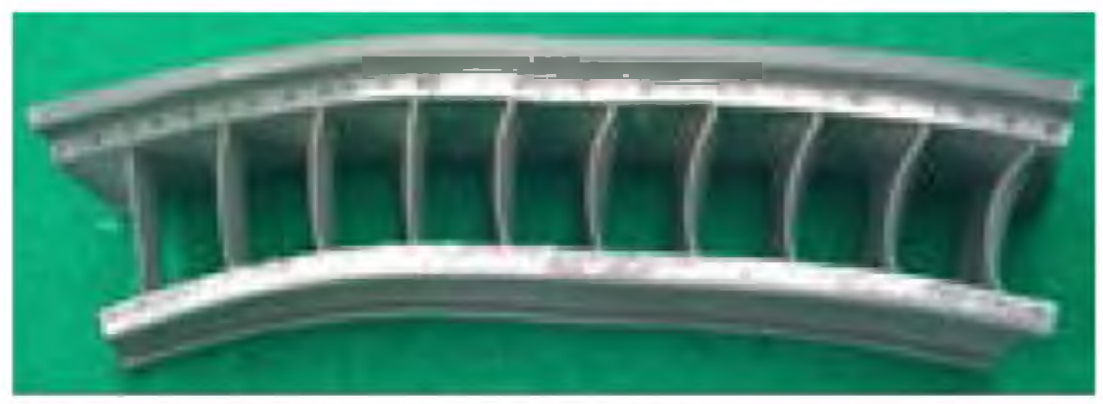

Fig. 13 Sintered vanes using conventional binder 


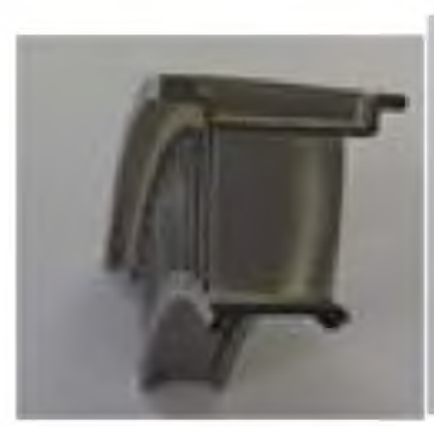

(a)

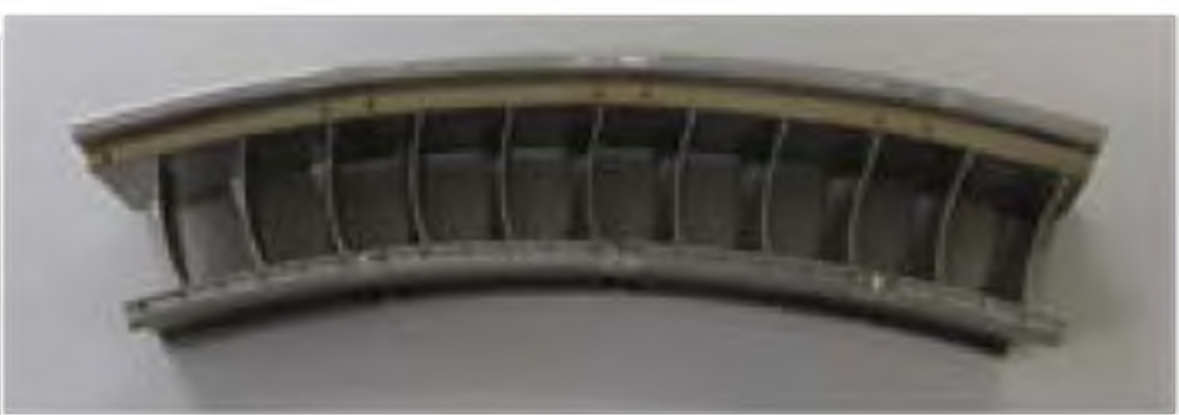

(b)

Fig. 14 Sintered prototype vanes using new binder

(a) Side view (b) front view

\section{Conclusion}

MIM materials were confirmed to have sufficient material strength for compressor vanes of jet engines that requires a high fatigue strength. Fatigue strength of MIM materials that were manufactured using new binder exceeds forging due to its fine grain size. Meanwhile fatigue strength of MIM materials is significantly affected by oxygen concentration. Therefore it is necessary to use gas atomized powder to obtain good fatigue strength. Yield and Tensile strength of MM materials are almost equivalent to forging. It was also found that using the new binder, deformation during de-binding and sintering is suppressed sufficiently.

\section{Acknowledgements}

A part of this study was supported by New Energy and Industrial Technology Development Organization (NEDO) as a part of "aircraft and space industry innovation program" and "energy innovation program" of Ministry of Economy, Trade and Industry (METI) Japan.

\section{Reference}

1. Randall M. German and Animesh Bose, Injection Molding Metals and Ceramics Metal Powder Industries Federation (1997), 175-218

2. J. J. Valencia, J. Spirko, and R. Schmees, Sintering effect on the microstructure and mechanical properties of alloy 718 proceeded by powder injection molding, Superalloy 718 , 625,706 and various derivatives, TMS, 1997, 753-762

3. Eric A. Ott, and Michael W. Peretti, "Metal Injection Molding of Alloy 718 for Aerospace Application", JOM , Vol. 64 No. 2 (2012), 252-265 